\title{
DISMINUCIÓN DE AGUDEZA VISUAL, PRIMER SÍNTOMA DE UN TUMOR MEDULAR
}

\section{VISUAL ACUITY LOSS, THE INITIAL SYMPTON OF A SPINAL CORD NEOPLASM}

\author{
MILLÁN-RODRÍGUEZ AC ${ }^{1}$, LÁZARO-GONZÁLEZ V ${ }^{2}$, DIOS-CASTRO E ${ }^{2}$, R. REGAL A ${ }^{1}$, \\ CORES FJ ${ }^{1}$, FERNÁNDEZ-VILA PC ${ }^{2}$
}

\section{RESUMEN}

Caso clínico: Se presenta el caso de una mujer de 46 años con disminución de agudeza visual en el ojo derecho y papiledema, con dilatación ventricular en la Resonancia Magnética Nuclear (RMN) cerebral. En la punción lumbar se detectó hiperproteinorraquia. La RMN medular reveló la presencia de una neoplasia de la médula espinal. La paciente recuperó la agudeza visual tras la extirpación quirúrgica del tumor, que resultó ser un neurilemoma. Discusión: Se comenta la presentación ocular y la fisiopatología de la hipertensión intracraneal en el tumor espinal. Asimismo se destaca la importancia del diagnóstico etiológico del papiledema.

Palabras clave: Papiledema, neoplasias de médula espinal, neurilemoma, hipertensión intracraneal, hidrocefalia.

\begin{abstract}
Case report: A 46-year-old woman, who presented with right visual acuity loss, was found to have papilledema, and subsequently shown to have ventricular dilatation in a cerebral Magnetic Resonance Imaging (MRI) assessment. Elevated protein levels were found in the cerebrospinal fluid. Spinal MRI revealed the presence of a spinal cord neoplasm. After surgical removal of the tumor, which turned out to be a neurilemmoma, the patient's visual acuity was restored.

Discussion: The ocular presentation and the relationship between intracranial hypertension and spinal tumors are discussed. Likewise, the importance of considering the various causes of papilledema is emphasized (Arch Soc Esp Oftalmol 2008; 83: 437440).
\end{abstract}

Key words: Papilledema, Spinal cord neoplasms, Intracranial hypertension, neurilemmoma, hydrocephalus.

\footnotetext{
Recibido: 6/11/06. Aceptado: 21/5/08.

Hospital Provincial. Complexo Hospitalario de Pontevedra. Pontevedra. España.

1 Licenciado en Medicina.

2 Doctor en Medicina. 


\section{INTRODUCCIÓN}

Los tumores cerebrales y el pseudotumor cerebri son causas frecuentes de papiledema. Es infrecuente, aunque conocido, el papiledema secundario a un tumor de la médula espinal (1). Se describe el caso de una paciente con un tumor medular que se presentó con disminución de la Agudeza Visual (AV) y papiledema.

\section{CASO CLÍNICO}

Mujer de 46 años de edad que acudió a la Consulta de Oftalmología por disminución de la visión en ojo derecho desde hacía un año. No refería dolor de cabeza, ni oscurecimientos transitorios, ni episodios de visión doble. Asimismo no había estado en tratamiento con Litio, tetraciclinas, vitamina A o corticoesteroides. No había variado de peso en el último año.

El examen neurológico era normal. En la exploración oftalmológica la agudeza visual corregida era 20/25 en el ojo derecho y 20/20 en el ojo izquierdo. El examen de polo anterior con lámpara

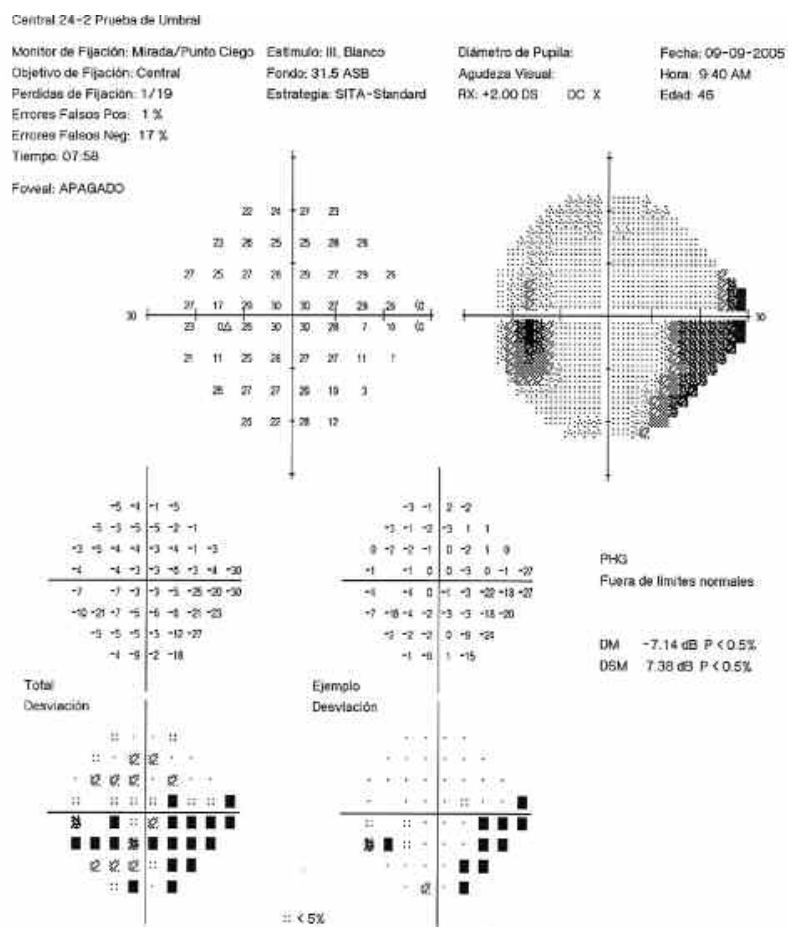

de hendidura, la presión intraocular, y la motilidad ocular extrínseca e intrínseca eran normales. En el examen de fondo de ojo se observaba discreta borrosidad y elevación de ambas papilas, sin hipe-

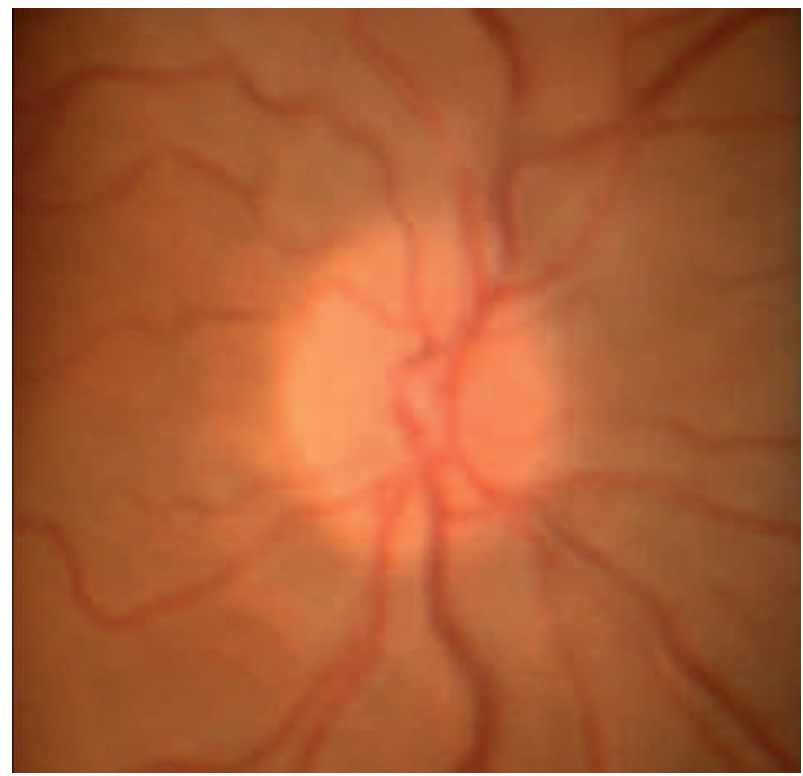

Fig. 1: Imagen de fondo de ojo derecho. En la papila se observa discreta borrosidad y levantamiento.

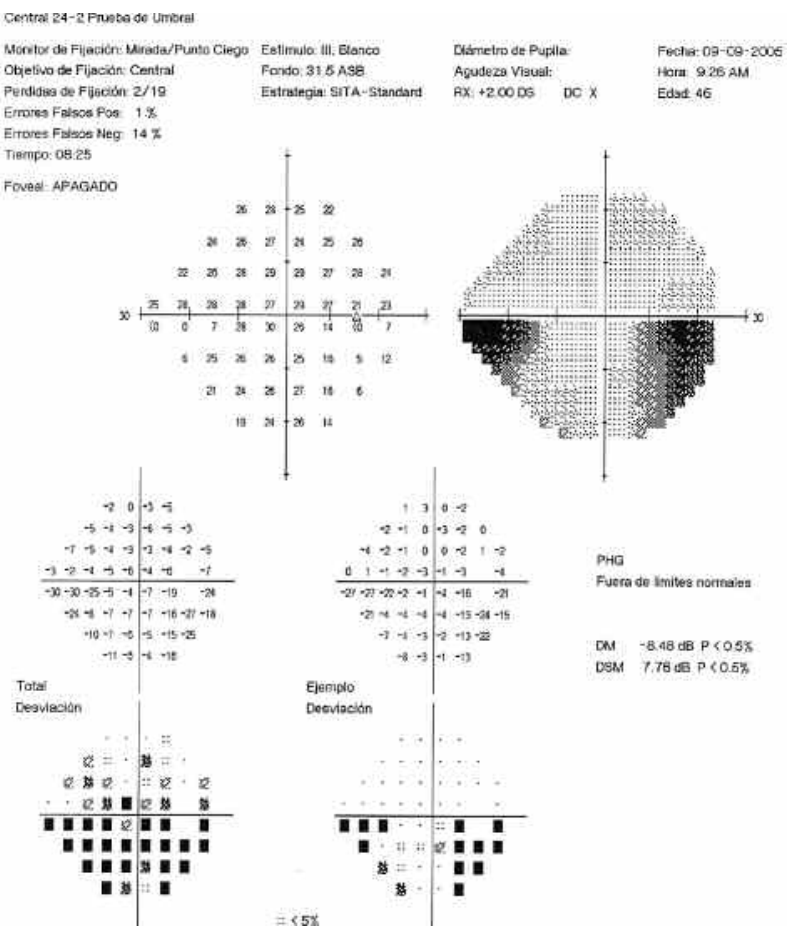

Fig. 2: Perimetría Humphrey 24-2 de los dos ojos. Se observa aumento de la mancha ciega con defecto nasal inferior en ambos. 
remia ni hemorragias, con mayor edema en la capa de fibras nerviosas de ojo derecho (fig. 1). En la Ecografía no se apreciaron drusas del nervio óptico. La exploración del campo visual con perímetro Humphrey (Carl Zeiss Meditec, Inc., Dublin, California) programa SITA 24-2 mostró incremento de la mancha ciega con defecto nasal inferior en ambos ojos (fig. 2).

En la resonancia magnética nuclear (RMN) cerebral se apreció dilatación moderada de sistema ventricular supratentorial sin objetivarse lesiones ocupantes de espacio. Con estos hallazgos, y sin existir contraindicaciones, se realizó una punción lumbar, con el objetivo de medir la presión del líquido cefalorraquídeo (LCR) y poder filiar la hidrocefalia, que reveló una presión de apertura elevada, $38 \mathrm{cmH}_{2} \mathrm{O}$ (normal 5-18 $\mathrm{cmH}_{2} \mathrm{O}$ ); y el análisis de (LCR) mostró proteínas totales muy elevadas, $794 \mathrm{mg} / \mathrm{dL}$ (normal $15-50 \mathrm{mg} / \mathrm{dL}$ ).

Se realizó entonces una RMN de médula espinal que detectó la presencia de una gran masa intradural, polilobulada, excéntrica a la médula sobre la que ejercía efecto masa, que se realzaba tras la administración de contraste y se extendía desde el cuerpo vertebral de T8 hasta el de T11, de $8 \times 2 \mathrm{~cm}$ (fig. 3). La paciente fue intervenida realizándose una laminectomía y la escisión de la lesión, cuyo informe anatomo-patológico fue de Neurilemoma.

A los tres meses de la intervención la paciente se había recuperado de sus problemas visuales, con práctica normalización de la perimetría y de la cabeza del nervio óptico, con cierta gliosis residual. A los seis meses se había resuelto la dilatación ventricular encefálica.

\section{DISCUSIÓN}

La presentación de un tumor medular sólo con afectación visual está descrita, pero es poco frecuente, habiendo encontrado únicamente siete casos en la literatura $(1,2)$. La clínica aislada de leve pérdida de $\mathrm{AV}$ en el ojo derecho y el papiledema poco manifiesto, en principio sugerían seudopapiledema por drusas. Pero con la alteración del campo visual, y tras descartar las drusas de nervio óptico por la Ecografía, se indicó la RMN cerebral y posteriormente la punción lumbar y la RMN espinal con lo que se estableció el diagnóstico.

Los tumores medulares raramente producen papiledema, Arseni y Maretsis revisaron 289 casos
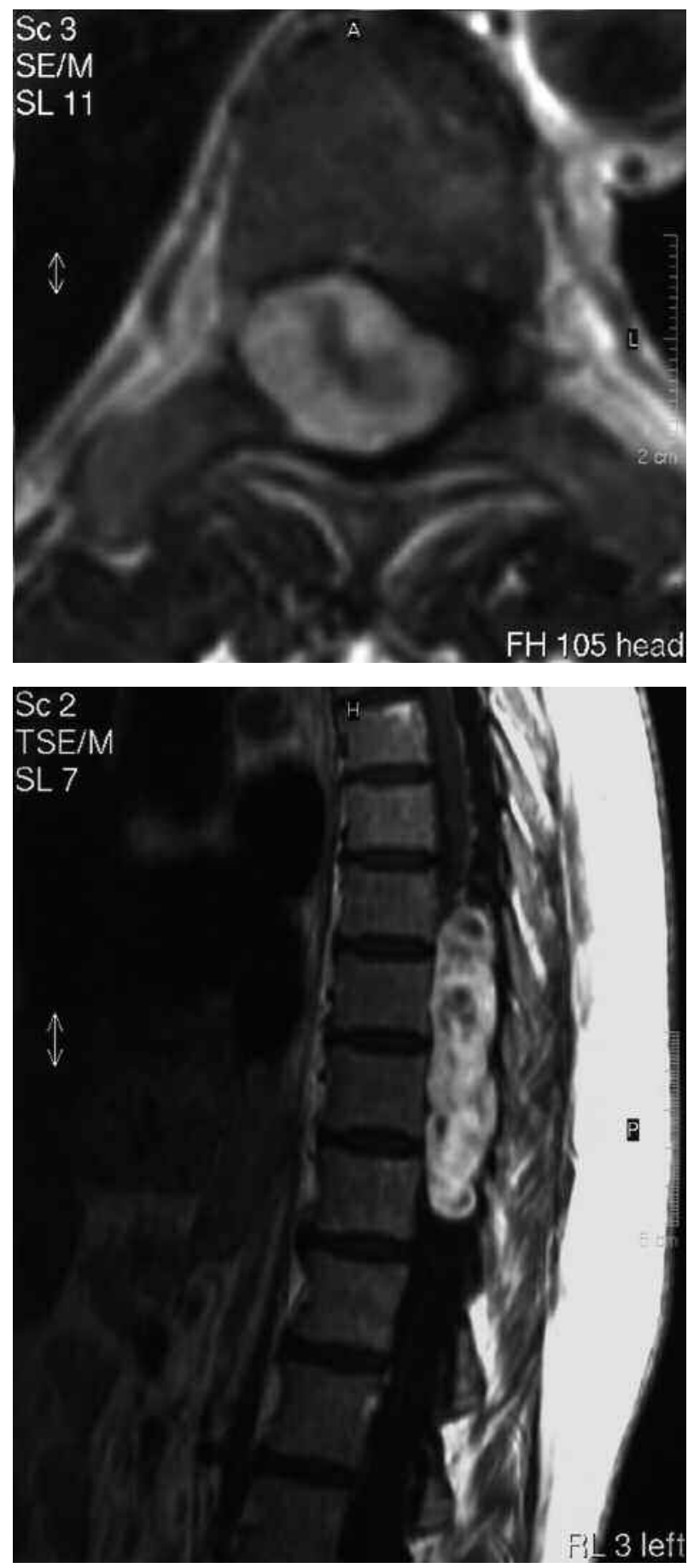

Fig. 3: RMN con contraste potenciada en Tl axial (a) y sagital (b) que demuestra la presencia de una masa intradural y extramedular.

y sólo tres presentaban papiledema $(1,3)$. Cuando lo producen el $40 \%$ de los casos son ependimomas y sólo el 11\% neurilemomas, también llamados 
schawnnomas (1). La clínica suele ser de dolor local y parestesias $(1,4)$. Cuando se presentan con papiledema es más frecuente la cefalea y la pérdida de visión $(1,3)$.

Los mecanismos postulados para la hidrocefalia con hipertensión intracraneal y papiledema en el tumor medular son diversos. En los tumores medulares altos puede ser la obstrucción local (4), mientras que en los torácicos, lumbares y sacros la elevación de las proteínas en el LCR podría obstruir el drenaje del mismo y producir inflamación de las leptomeninges (1-3,5). Otro mecanismo que se atribuye a los tumores espinales bajos es la reducción de la reserva elástica lumbosacra, que produciría la obstrucción mecánica del líquido cefalorraquídeo a ese nivel con el consecuente aumento de presión (14). En nuestra paciente la hiperproteinorraquia y la gran extensión del tumor que podría comprimir el drenaje venoso epidural, explicarían el desarrollo de la hipertensión intracraneal (4).
Como conclusión destacar la importancia del diagnóstico etiológico del papiledema y la necesidad de realizar RMN medular, en un paciente con papiledema, RMN cerebral con dilatación ventricular y aumento de proteínas en LCR, aún sin clínica medular.

\section{BIBLIOGRAFÍA}

1. Matzkin DC, Slamovits TL, Genis I, Bello J. Disc swelling: a tall tail? Surv Ophthalmol 1992; 37: 130-136.

2. Costello F, Kardon RH, Wall M, Kirby P, Ryken T, Lee AG. Papilledema as the presenting manifestation of spinal schwannoma. J Neuroophthalmol 2002; 22: 199-203.

3. Zhang Y, Lao Y, Guo Y, Guo H. Bilateral papilloedema associated with lumbo-sacral intraspinal tumor. Chin Med $J$ (Engl) 2000; 113: 201-205.

4. Amlashi SF, Riffaud L, Morandi X. Communicating hydrocephalus and papilloedema associated with intraspinal tumours: report of four cases and review of the mechanisms. Acta Neurol Belg 2006; 106: 31-36.

5. Tanaka K, Waga S, Shimosaka S. Papilledema and spinal cord tumors. Surg Neurol 1988; 29: 462-466. 